\title{
Tempest in a teapot: The exaggerated problem of transport-related residential self-selection as a source of error in empirical studies
}

\section{Petter Næss ${ }^{\text {a }}$}

\author{
Norwegian University of Life Sciences
}

\begin{abstract}
While numerous studies have investigated influences of built environment characteristics on travel behavior, many scholars are concerned about the confounding effect of residential self-selection. This paper argues that the existence of transport-attitude-based residential self-selection hardly represents any threat to the validity of the basic knowledge on how residential location within urban contexts influences travel behavior. The causal mechanisms by which residential location influences travel behavior exist regardless of whether or not transport-related residential self-selection occurs. Moreover, the cases presented in this paper suggest that residential self-selection based on attitudes to travel is unlikely to represent any great source of error for parameter estimates of the effects of residential location variables on travel behavior as long as "traditional" demographic and socioeconomic variables have already been accounted for. The doubts raised by certain scholars about the implications of attitude-based residential self-selection for the validity of the knowledge base of land use and transportation policies thus appear to be not very well-founded.
\end{abstract}

\section{Introduction}

Although a large number of studies carried out in different countries over the last three decades have documented the association between the built environment and travel behavior, many scholars are concerned about the confounding effect of "residential self-selection," which means that people choose their residential location based on their travel preferences and needs. For example, persons who dislike driving may choose to live in neighborhoods well-served by public transportation and travel more often by transit. Although the majority among recent studies about residential self-selection ${ }^{1}$ seems to conclude that both residential location and travel preferences are significant predictors of travel behavior (Cao et al. 2009 and 2010), it has been argued by some authors that residential location may not per se influence travel patterns in such cases, but instead that travel preferences do (e.g., Kitamura et al. 1997; Boarnet \& Crane 2001; van Wee 2009 and 2013). Other authors, while acknowledging the influences of both residential location and travel preferences, hold that the influence of residential location on travel behavior tends to be significantly exaggerated unless travel-based residential selfselection is controlled for (e.g., Bagley \& Mokhtarian 2002; van Acker \& Witlox 2010; Bothe 2009 and 2010). Based on such sources within the transport research literature, several secondary sources (notably within urban planning literature), such as Bruegmann (2005), have referred to disputes and uncertainties on the "self-selection problem" to raise doubt as to whether combatting urban sprawl is worthwhile. The present paper counters the above-mentioned positions. As will be argued below, the

\footnotetext{
a petter.nass@nmbu.no
}

${ }^{1}$ In some of the literature on urban form, travel behavior and residential self-selection (e.g., Cao 2010 and Cao et al. 2010), the latter concept is used in a way including residential location choices based on transport attitudes as well as on demographic and socioeconomic characteristics. The topic of the present paper is, however, the role of self-selection based on travel-related residential preferences as a potential source of error in investigations of the influences of residential location on travel behavior in an urban context.

Copyright 2014 Petter Næss

Licensed under the Creative Commons Attribution - NonCommercial License 3.0. 
causal mechanisms by which residential location influences travel behavior exist regardless of whether or not transport-related residential self-selection occurs. To the extent that such self-selection represents any methodological problem in studies of the influences of residential location on travel, it concerns the accuracy of attempts to quantify the magnitudes of these influences. The examples given in this paper suggest that residential self-selection based on transport attitudes hardly represent any important source of error in quantitative studies of relationships between residential location and travel as long as control is made for "ordinary" demographic and socio-economic characteristics of the respondents such as income, gender, age, household characteristics, education, workforce participation, etc. The worry among scholars, in particular in North America, about the implications of attitude-based residential self-selection for the knowledge base of land use and transportation policies is therefore, in my opinion, considerably exaggerated.

My line of argument goes as follows:

a) The causal mechanisms by which residential location influences travel behavior are wellunderstood theoretically and empirically well-documented

b) Transport-related residential self-selection is in itself a demonstration of the influence of residential location on travel behavior

c) Exact, context-independent quantification of effects of residential location is neither possible nor necessary for reasonable land use policymaking

d) Travel attitudes are not necessarily antecedent to choices of residential location but may themselves be influenced by residential location

e) People may have preferences for particular modes, but does anyone prefer to drive long distances rather than short?

f) Activity preferences may be just as important as travel preferences in attitude-based residential self-selection

g) Travel attitudes are not the most important criteria of residential preferences, and several constraints can prevent people from realizing what they would otherwise prefer

Arguments $\mathrm{a}-\mathrm{c}$ seek to establish that existing knowledge already enables planners and policy-makers to design urban land use strategies favorable to promote transport policy goals such as reducing greenhouse gas emissions, energy consumption and car dependency. If we want urban land use policies to contribute to such goals, we know a lot of what kinds of land use should be preferred and what kinds should be avoided. We know, for example, that urban outward expansion and low-density development will normally cause more car travel than urban densification. The existence of attitude-based residential knowledge does not represent any threat to the validity of this basic knowledge. Moreover, due to the social, spatial and temporal context-dependence of each urban planning situation, exact predictions of the transport effects of a given urban developmental strategy are not possible. Therefore, using more sophisticated statistical techniques to measure the contribution of attitude-based self-selection to geographical variations in residents' travel behavioral patterns is maybe not such a big deal. Knowledge about the order of magnitude of the likely effects in different urban contexts will arguably be sufficient for informed policymaking and planning.

If exact estimates of the travel behavioral effects of residential location are still considered important, arguments $\mathrm{d}-\mathrm{g}$ aim to demonstrate that residential self-selection based on attitudes to travel are unlikely to represent any great source of error if "traditional" demographic and socioeconomic variables have already been accounted for. Rather than doing increasingly sophisticated studies to quantify the relative importance of built environment characteristics and residential self-selection to travel behavior, scholars should put more energy into investigating questions hitherto not covered by much research, 
such as whether, and in case how and why, residential location influences travel differently in different kinds of cities and across population groups.

Besides presenting theoretical arguments, the paper will draw on empirical studies conducted by myself and colleagues in different cities, especially the studies in Copenhagen Metropolitan Area, Denmark (Næss 2005, 2006a and b, 2009, and 2011), Hangzhou Metropolitan Area, China (Næss 2010 and 2013) and a still on-going study in Greater Oporto, Portugal (Pinho \& Silva 2015). All these studies have been carried out by means of a combination of qualitative and quantitative research methods. The Copenhagen Metropolitan Area study included 17 qualitative interviews with residents living in five different (inner-city and suburban) neighborhoods, a questionnaire survey comprising 1932 respondents from 29 selected residential neighborhoods, and a travel diary follow-up survey completed by 273 of the respondents of the first survey. The Hangzhou study Metropolitan Area included 28 qualitative interviews with residents living in five neighborhoods representing different metropolitan contexts, as well as a questionnaire survey answered by 3155 respondent from a large number of neighborhoods distributed over the metropolitan area. The Greater Oporto study was first carried out only as a questionnaire study (cf. Næss, Silva \& Pinho 2011), but has later been expanded to include also a number of qualitative interviews. In the present paper, the material drawn on from the Oporto study will only be the interview material. In each of the three city cases, the interviews, each lasting for 1 to 2 hours, were audio-recorded and transcribed. Due to missing answers to some questions, the survey material used in subsequent multivariate analyses includes a lower number of respondents than the number of returned questionnaires. More details about the methods of each study can be found in the publications cited above. The purpose of the present paper is not to once again present the methodology and bring the main results of these studies, but instead to highlight some aspects that can help shedding light on the issue of residential self-selection.

\section{Self-selection as a methodological problem}

In standard literature on social science surveying methods, self-selected samples are mentioned as an important source of error (see, e.g., Heckman 1979). For example, when television program hosts make a poll among the watchers of a debate program whether they consider a certain phenomenon to be a problem or not, those who consider the phenomenon problematic may be more prone than their more indifferent counterparts to watch this particular program and dial their opinion to the TV channel. Correspondingly, in connection with studies of the influence of land use on travel, some commentators have pointed to the fact that people who for other (non-urban-structural) reasons are prone to travel a lot by car, may prefer to move into suburban neighborhoods matching their preferences, i.e., locations where roads are wide and relatively non-congested, and with ample parking space. Conversely, people who do not like to (or are not able to) travel by car may choose a residential location where other modes of travel are facilitated to a higher extent than car driving. When researchers find, e.g., correlations between inner-city residential location and a low amount of travel by car this relationship might thus be caused not by the location of the dwelling in itself, but by individual characteristics of the residents (e.g., their income level or certain attitudes predisposing them to minimize on car travel or abstain from owning a car). The problem of self-selection occurs if such individual characteristics have not to a sufficient extent been controlled for.

Nowadays, studies of the influence of urban structure on travel behavior without some multivariate control for non-urban-structural variables are relatively uncommon. Most studies on the topic since the early 1990s include control for several demographic and socioeconomic variables such as gender, age, household characteristics, employment status, and income. Despite such control, in situations where attitude-based residential self-selection may occur it is sometimes argued that land use and transporta- 
tion patterns as such do not influence travel patterns, but instead that travel preferences do. Or at least it is argued that the influence of residential location on travel will be overestimated unless separate control is made for attitude-based residential self-selection (Handy 1996; Kitamura et al. 1997; Bagley \& Mohktarian 2002; van Wee 2009 and 2013).

\section{Causal influences of residential location on travel exist, regardless of residential self-selection}

At best, the claim that the problem of self-selection makes the results of empirical studies carried out until now inconclusive is imprecise and needs qualification. Does self-selection raise doubt about the existence of any influence of residential location on travel behavior, or about the magnitude of such an influence? Elaborating on the statements $a-c$ mentioned in the introductory part, arguments will be put forth below against the first of these assumptions, i.e., against the idea that residential self-selection gives reason to doubt whether there exist causal influences of residential location on travel behavior.

\section{a) The causal mechanisms by which residential location influences travel behavior are well-understood theoretically and empirically well-documented}

Theories of transport geography and transport economy consider the travel between different destinations to be influenced on the one hand by the reasons people may have for going to a place, and on the other hand by the costs and inconvenience involved when traveling to this location (Jones 1978). The urban structural situation of the dwelling influences how long or short distances the residents will need to travel in order to reach various opportunities for activities (job, school, shopping, leisure activities, etc.), and which means of transportation will be possible and attractive to use for these trips (Christaller 1966; Hägerstrand 1970; Boarnet \& Crane 2001). Despite decentralizing trends, most cities—at least in Europe-still have a higher concentration of workplaces, retail businesses, public agencies, cultural events, and leisure facilities in the historical urban center and its immediate surroundings than in the peripheral parts of the urban area. For residents in the inner and central parts of the city, distances will be short to this concentration of facilities, which offers the largest supply of work opportunities, the broadest range of commodities in the stores, and the highest diversity of services (Berry \& Garrison 1958). Downtown is usually also close to the geographical center of gravity of the jobs and service facilities that are not themselves located in the city center (Nielsen 2002). Therefore, the distances to suburban workplaces and facilities will also be on average shorter for those living close to the city center. Local-area densities are usually also higher in the inner parts of cities than in the peripheral suburbs. With a higher density of residences or workplaces in the local area, the population base for various types of local service facilities will increase. Hence, the average distance from residences to local services will also be shorter. Inner-city residents could thus be expected, on average, to make shorter daily trips than their outer-area counterparts to both local and more specialized facilities, and a high proportion of destinations might be easily reached on foot or by bicycle.

In addition, local-scale urban design principles, such as street pattern, availability of sidewalks and bike paths, etc., and aesthetic neighborhood qualities, can influence the attractiveness of non-motorized travel modes and can for some travel purposes also affect trip destinations.

In order to demonstrate empirically that residential location is a (contributory) cause of differences in travel behavior, the basic mechanisms by which residential location influences travel behavior must be identified. Examples showing the rationales on which people base their frequency of participation in out-of-home activities, the locations of these activities, the modes of travel used to reach these locations, and the routes followed make up important links in the mechanisms by which urban structures 
influence travel behavior. Transport rationales are understood here as the backgrounds, motivations, and justifications that agents draw on when they make transport-relevant decisions about their participation in activities, location of these activities, modes of transportation, and the routes followed (Næss \& Jensen 2005, p. 165, see also Beckmann 2001). Combined with the spatial configuration of residences, employment, and other facilities in a city or metropolitan area, the transport rationales produce some characteristic relationships between residential location and travel found in a number of different urban contexts.

According to Røe (2001), the mobility lifestyle of most of inhabitants in modern, affluent cities could be characterized as spatially flexible. Typical for this mobility lifestyle is that proximity is of minor importance when choosing where to live, work, and carry out leisure activities. The social networks are also spread over a large area, sometimes including exurban areas. Some inhabitants still have few mobility resources and their mobility lifestyle is therefore less flexible, based to a high extent on public transportation. However, for both mobility lifestyle groups, residential location has a bearing on travel behavior. For the highly flexible individuals, residential location in the inner city, with its many facilities in near proximity of the dwelling, allows choices among the many services in the vicinity of the dwelling as well as elsewhere in the urban region. In contrast, people belonging to the same mobility lifestyle group and living at the outskirts of the city need to travel long distances in order to meet their preferences. For inner-city residents with less flexible mobility lifestyles, availability of a wide range and number of facilities within a relatively short distance from the dwelling allows many opportunities for choice despite these interviewees' relatively confined geographical radius of action. Members of the lowmobility lifestyle group living in the suburbs are, however, experiencing several spatial constraints and a low degree of freedom of choice, especially if the area is poorly served by public transportation. (Røe 2001.)

The tendency of high-mobile inhabitants of modern cities to emphasize (within some threshold distances) the possibility of choosing among facilities rather than proximity means that the amount of travel is influenced to a higher extent by the location of the residence in relation to concentrations of facilities, rather than the distance to the closest single facility within a category. This is especially true as regards workplaces. Daily traveling distances, therefore, tend to be more influenced by the distance from the dwelling to the city's main concentration of facilities (usually the inner city) than by its distance to local centers. For non-specialized leisure and daily routine activities (such as grocery shopping), more emphasis is placed on proximity, especially among less mobile population groups (Næss 2005, 2006a). Similar transport rationales have been identified in a number of Nordic studies (Røe ibid.; Tillberg 2001; Nielsen 2002; Næss \& Jensen 2004; Næss 2005 and 2006a) as well as in Oporto, Portugal (Pinho \& Silva 2015) and Hangzhou, China (Næss 2013). This similarity across widely differing contexts suggests that there may be a high degree of generality of the basic mechanisms through which urban form influences travel behavior.

Based on the above-mentioned qualitative studies, choices of travel modes are influenced by two main groups of interconnected rationales:

- Rationales concerning the efficiency of the movement from origin to destination, related to time consumption, economic costs and accessibility benefits of traveling by different modes

- Rationales concerning the process of moving from origin to destination, related to physically, psychologically and socially positive or negative aspects associated with traveling by a particular mode

Several of the rationales are hinted at indirectly through a criterion of trip distance as an important condition influencing the interviewees' choices of travel modes. Since long trips will be very time-consuming as well as physically exhausting if they are made by non-motorized modes (in particular by foot), rationales of time-saving and limitation of physical efforts will logically imply a dependence of travel 
modes on trip distances. Living close to relevant trip destinations, as inner-city dwellers tend to do more often than their suburban counterparts, thus does not only contribute to shorter traveling distances, but also implies a higher propensity of using non-motorized modes.

In our questionnaire surveys in the metropolitan areas of both Copenhagen and Hangzhou, questions were asked about residential preferences. Based on the answers to these questions, dummy variables for transport-related residential preferences were computed. In the Copenhagen study, the dummy variable for transport-related residential preferences was based on the respondents' selection of the three residential characteristics they considered most important among a battery of 17 characteristics. Respondents selecting one or more (out of four) characteristics representing proximity to public transport and daily destinations were given the value 1 , while respondents not giving priority to any such feature of the dwelling were giving the value 0 . The four characteristics were the following ones: "Short distance to the workplace," "Close to shopping facilities," "Close to rail station" and "Close to bus stop." In the Hangzhou study, respondents were in a similar way asked to select and prioritize three out of 20 characteristics that would be most important if they were to move from their present residence to a new dwelling. Respondents whose two highest-rated residential characteristics included one of the four above-mentioned characteristics were assigned a value of 1 , while the remaining respondents received a value of 0 .

In both city cases, a comparison was made of the relationship between residential location and traveling distance by car among respondents with and without transport-related residential preferences. In both metropolitan areas, there was a clear tendency in each group of respondents of longer travel distances the further away from the city center the respondents were living (Næss 2009 and 2010). Moreover, in each city region separate analyses were also made for residents living at locations poorly matching their transport-related preferences (dissonant residents) and those who live at locations where their residential preferences are met (consonant residents) (cf. Schwanen \& Mokhtarian 2004; Cao et al. 2009). As can be seen in Figure 1, travel distances by car in both city regions increase the further away from the city center the residence is situated both among consonant and dissonant residents. Not surprisingly, the difference between suburbanites and inner-city dwellers in the amount of car traveling is greater in the consonant group, which consists of inner-city dwellers who consider proximity to public transport, employment, and/or shopping opportunities important and suburbanites who do not think these characteristics are important. But also in the dissonant group, consisting of suburbanites who do consider proximity to public transport, employment, and/or shopping opportunities important and inner-city dwellers who do not think these characteristics are important, we find a pattern in each city region of longer traveling distances by car among respondents living in the suburbs than among their inner-city counterparts (Næss 2009 and 2010). Among Hangzhou respondents, there is a slight tendency that mismatched suburban residents are less likely to exercise their preferences because of the built environment than mismatched urban residents, resembling findings by Schwanen \& Mohktarian (2004). The main point is, however, that suburbanites drive longer distances than inner-city dwellers both in the consonant and the dissonant group. If transport-related residential self-selection were the main reason for geographical differences in travel behavior, inner-city residents who do not consider proximity to public transport and daily destinations important could instead be expected to drive longer distances than suburbanites who do consider such characteristics of the dwelling important.

The above-mentioned relationships between the distance from the dwelling to the city center and traveling distance by car hold true also when carrying out multivariate statistical analyses controlling for demographic and socioeconomic variables as well as for transport-related residential preferences. This applies not only to the influence of residential location on traveling distance by car, but also on total weekly traveling distances, travel by non-motorized modes, and travel by public transport (most of these results are reported in Næss 2009; Næss 2010; and Pinho \& Silva 2015). The demonstration of a 

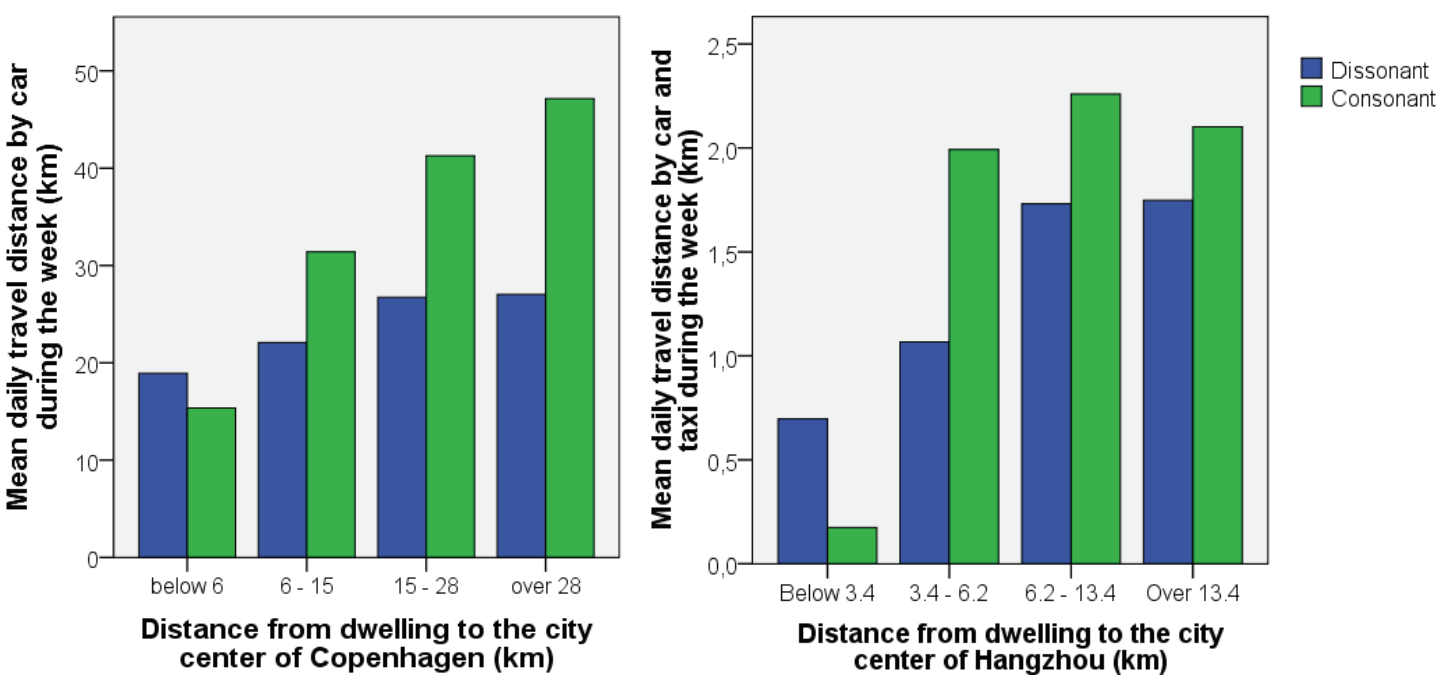

Figure 1: Mean travel distances by car on weekdays among dissonant ("mismatch") and consonant ("match") residents living in different distance intervals from the city centers of Copenhagen (left) and Hangzhou (right).

Copenhagen: $\mathrm{N}=1793$ in total (of which 861 consonant and 932 dissonant), varying from 401 to 526 in the different distance intervals. Hangzhou: $\mathrm{N}=2829$ in total (of which 1537 consonant and 1292 dissonant), varying from 655 to 791 in the different distance intervals. (Please notice the different scales of the vertical axes.)

separate and considerable effect on travel behavior from the location of the dwelling relative to the city center, also when controlling for socio-demographics and residential self-selection, is in line with the findings by Hammond (2005), Bhat \& Guo (2007), Zhou \& Kockelman (2008), Chatman (2009), Cao (2010), and Cao et al. (2010).

The conclusions from the above-mentioned studies add to the quite overwhelming international evidence that urban spatial structures matter to travel behavior and are in line with what could be expected from theoretical insights within fields such as transportation geography (Tobler 1970; Jones 1978; Fox 1995), time-geography (Hägerstrand 1970), and central place theory (Christaller 1966; Berry \& Garrison 1958).

Importantly, these causal mechanisms by which residential location influences travel distances and modes exist whether or not any transport-related residential self-selection takes place. The issue raised about attitude-based residential self-selection is therefore not whether causal influences exist of residential location on travel behavior. The concern is instead whether the autonomous influences of built environment characteristics on travel are "large enough to matter" (Cao et al. 2009).

\section{b) Transport-related residential self-selection is in itself a demonstration of the influence of residential location on travel behavior}

As argued earlier by Næss \& Jensen (2000), Næss (2005, 2006 a and b, 2009) and Chatman (2009), the fact that people to some extent "self-select" into areas matching their transport attitudes is in itself a demonstration of the importance of urban structure to travel behavior. If there were no such influence, people who prefer to travel by non-motorized modes might as well settle in the peripheral part of the metropolitan area, far away from the concentration of workplaces and service facilities found in the central and inner city.

For transport-attitude-based residential self-selection to exist there must thus already exist some residential areas whose influences on travel needs and travel opportunities are such that potential movers find reasons to self-select themselves into becoming residents of these neighborhoods. The (perceived) 
causal mechanism between residential location and travel must therefore exist prior to residential selfselection. This causal influence cannot be explained away by subsequent attitude-based choices of residential locations.

Here, it might be objected that people may possibly be wrong when assuming that it will be easier to realize a car-independent lifestyle in an inner-city setting than in the urban periphery (and conversely to realize a car-based lifestyle in the suburbs than in a neighborhood close to downtown). However, such large-sale misconceptions among urban populations do not appear to be very likely, given the fact that urban residents make their own experiences about their need for traveling at different locations in the city and can compare the situation of their present dwelling with previous places of residence. They can also share their experiences with colleagues and friends.

In the qualitative interviews of the above-mentioned studies in Copenhagen Metropolitan Area, Hangzhou Metropolitan Area and Greater Oporto, a clear tendency can be found that interviewees living in inner districts and/or close to main public transport lines mention accessibility or reduced needs for transport as important positive features of the neighborhood and/or reasons for living there, while interviewees living in neighborhoods with poor availability of facilities do not. The only exceptions are two suburban interviewees (one in Oporto and one in Hangzhou) who point at the proximity of their employer-provided dwellings to their workplaces.

The fact that most of the interviewees living in central districts or sub-centers well-served by public transport mention accessibility or reduced needs for transport as important elements of their residential preferences, while those living in neighborhoods with poor transit provision and low availability of facilities do not, could be interpreted as an indication of transport-related residential self-selection. But such self-selection hardly undermines the causal relationships between urban structures and travel behavior. Rather, emphasis on accessibility to jobs and other facilities is an example of the rationale of minimizing the friction of distance. Similar to how this rationale, together with a rationale of choosing the best facility, influences residents' locations of their activities, the rationale of minimizing the friction of distance will also, when key trip destinations (particularly the workplace) are seen as the base, influence people's choices about where to live, together with the rationale of choosing the best facility. In this case, "the best facility" refers to amenities of the residence other than its distance to the workplace and other frequent trip destinations, such as housing costs, availability of a private garden, absence of noise and air pollution, socioeconomic characteristics of the neighborhood, etc.

\section{c) Exact, context-independent quantification of effects of residential location is neither possible nor necessary for reasonable land use policymaking}

If urban planning is to contribute to the development of future urban land use in a way that is favorable for society, it must be possible to predict whether or not a proposed measure, for example the location of a new residential area, is likely to result in a different (and better) goal-achievement than alternative solutions. Predicting the future effect of a measure implies to make a generalization from a causal relationship existing today to a future relationship between cause and effect. Prediction can therefore be considered a generalization between different periods of time. Also a judgment of the present validity of older research results implies such a generalization. Studies of land use and travel are seldom published in scientific journals until at least a couple of years after the data collection, and the practical use of the results (e.g., in land use planning) takes place for a number of years after the publication of the results.

Cities can be considered as examples of systems of organized complexity (Weaver 1948; Jacobs 1961). Although not completely chaotic and open, they are far from the closed conditions of the natural science experiment, where the disturbing effects of confounding factors of influence has been artificially 
prevented, and where the outcome of an experiment can be predicted with certainty if the operating causal mechanism is known. For trips made regularly as a part of daily life, such as journeys to work or education, trips to the grocery store, and trips to bring children to kindergarten or school, a relatively high degree of closure — or restraint—still exists. The spatial location of the residence in relation to these functions and facilities, in combination with time-geographical restrictions (including the residents' obligations and needs to visit these destinations daily or regularly, cf. Hägerstrand 1970) could be characterized as a partially closed system.

Several theorists of science (e.g., Bhaskar 1998; Sayer 1992) have pointed at the difficulties in taking into account all the other factors of influence working in open systems when trying to predict how the future situation will be after the introduction of a given policy measure. Transferred to the context of land use and transport, this implies that it is impossible to predict, for example, the average number of kilometers traveled by the inhabitants of the Copenhagen Metropolitan area by 2025 if all new residences built from now on were to be located to Copenhagen's inner city. Among other things, the general development of mobility in Denmark is a factor of great uncertainty, depending on a number of economic, cultural and political conditions.

This still does not rule out the possibility of making a research-based assessment of the effect of such an urban developmental strategy on local transport, compared to an alternative location of residences. With a high probability, the consequence of urban densification would be a reduced amount of travel, compared to greenfield development at the outskirts of the urban area. However, it will not be possible to make any exact quantitative prediction of the effect. Predictions based on studies of residential location and travel will inevitably depend on a number of judgments, such as: Does it seem reasonable to assume that the situation in the future will be different in ways that are likely to change significantly the present relationships between urban structure and travel behavior? In case, which traits of development might be expected to alter present relationships? One might, for example, argue that a possible future increase in fuel prices (e.g., due to international agreements on greenhouse gas emissions) is likely to reduce much of the "optional" traveling, e.g., leisure trips. The remaining trips, e.g., between residences and jobs, schools and stores, depend to a higher extent on urban structural conditions. In such a scenario, the relative importance of urban structure to travel behavior is therefore likely to increase, and the negative social and welfare consequences of living in an area far from relevant facilities will be more serious. On the other hand, if the general mobility continues to increase, trips within the urban region are likely to account for a lower share of the total amount of travel. The relative importance of the location of activities within the urban region to the amount of transport will then decrease. (Measured in absolute figures, the influence of residential location on energy use may still increase, as a rising level of mobility probably implies that people will transport themselves more within the urban area as well.)

The need for generalizing across geographical contexts adds to the above difficulties in making exact predictions. Usually, planners will need to draw on knowledge based on research carried out in other cities or urban districts than the particular geographical area they are dealing with in the planning situation at hand. A planner in Stockholm wishing to locate new residences in a transport-reducing way may then consider whether the context in her city is sufficiently similar to the Copenhagen situation that the relationships between residential location and travel found in Copenhagen metropolitan area are likely to be present in the metropolitan area of Stockholm too. If similar results to those in Copenhagen have also been found in a number of other European cities, the evidence may be considered more compelling. The planner may then conclude that it is more likely than not that suburbanites living in the outer parts of Stockholm metropolitan area will travel longer distances than those living in the inner parts of the Swedish capital. This assessment will by nature be judgmental, and it would, for example, not be appropriate to copy a regression coefficient found in Copenhagen to predict how large increase there 
will be in vehicle $\mathrm{km}$ per capita in Stockholm per kilometer increase in the distance from the dwelling to the city center.

In principle, the possible types of predictions that planners can make from studies of residential location and travel will therefore be qualitative "rules of thumb", stating the direction of influence (more or less transport) and perhaps some order of magnitude. Realizing this has important implications for the meaningfulness of the quest for exact quantitative assessments of the effects of residential location on travel behavior. If the predictions of the likely travel impacts of proposed land use alternatives can anyway not be very accurate, the use of increasingly sophisticated statistical techniques to measure the contribution of attitude-based self-selection to geographical variations in residents' travel behavioral patterns is maybe not so important?

\section{Attitude-based residential self-selection: hardly a great source of error}

Above, I have argued that transport-attitude-based residential self-selection does not give rise to doubt about the existence of causal relationships between residential location and travel, and that exact quantification of the relative contributions of residential location and self-selection to geographical differences in travel behavior is hardly necessary for planning practice. Being aware that several scholars might disagree especially with the latter statement, I will in the following put forth arguments for the plausibility that residential self-selection represents only a minor source of error for the quantification of travel behavioral effects of residential location in studies where only "traditional" demographic and socioeconomic control variables have been included.

\section{d) Travel attitudes are not necessarily antecedent to choices of residential location but may themselves be influenced by residential location}

Many studies have attempted to assess the relative strengths of the influences of built environment characteristics and attitudinal variables on travel behavior (see, e.g., Cao et al. 2009). From the perspective of urban planning, the main interest is, however, the influence of the built environment. From a planner's perspective, it is of less importance whether other factors of influence (such as income, gender, employment status, or attitudes) exert stronger influences than those of the built environment. These latter factors are anyway outside the scope of what can be (directly) influenced through urban land use planning, as distinct from built environment characteristics, which are the very object of such planning. The important thing for an urban planner is therefore whether or not there is a non-negligible causal influence of built environment characteristics on travel behavior. From a planner's perspective, the concern about residential self-selection arises from the need to ensure that an observed association between built environment characteristics and travel behavior is not the spurious result of the fact that unmeasured attitudes are causing both (Cao et al. 2009).

For such spuriousness to occur there must be a unidirectional influence from attitudes to residential location (or at least a much stronger influence in this direction than in the opposite direction). However, as illustrated in Figure 2 (inspired by Cao et al. 2009), the conditions leading to spurious relationship between built environment characteristics and travel behavior (in this case car driving) make up only some of the possible situations where self-selection may occur. As argued earlier by Næss \& Jensen (2000), Bagley \& Mohktarian et al. (2002), Næss (2005 and 2009 and Bothe et al. (2009), people may choose their residential location based on a wish to realize a certain transport lifestyle, but their transport attitudes may also be shaped by the needs for mobility, travel opportunities and transport cultures characterizing their residential neighborhood. Arguably, the situation shown in the bottom right quadrant of the figure (IV) is more plausible and common than those in the upper part (I and II) where spurious 
associations occur. In example (IV), the built environment exerts a direct influence on travel behavior, whereas both the relationships between attitudes and the built environment and the relationships between attitudes and travel behavior are bidirectional.

\section{a. Attitudes Antecedent}

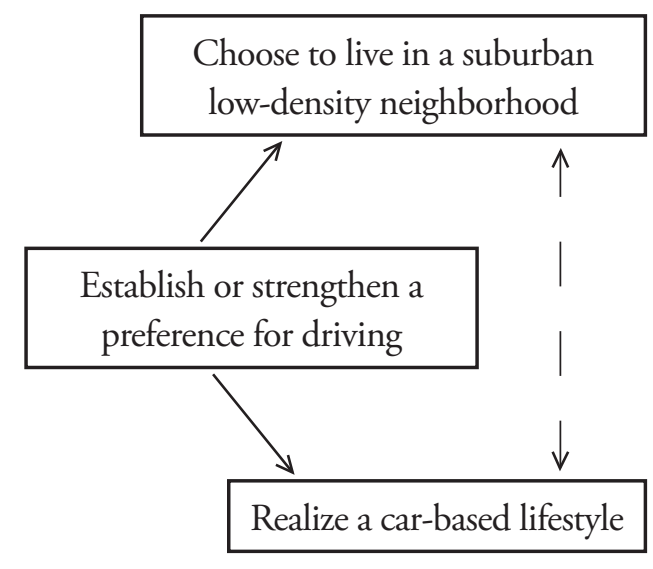

c. Attitudes Intervening

(in the other direction)

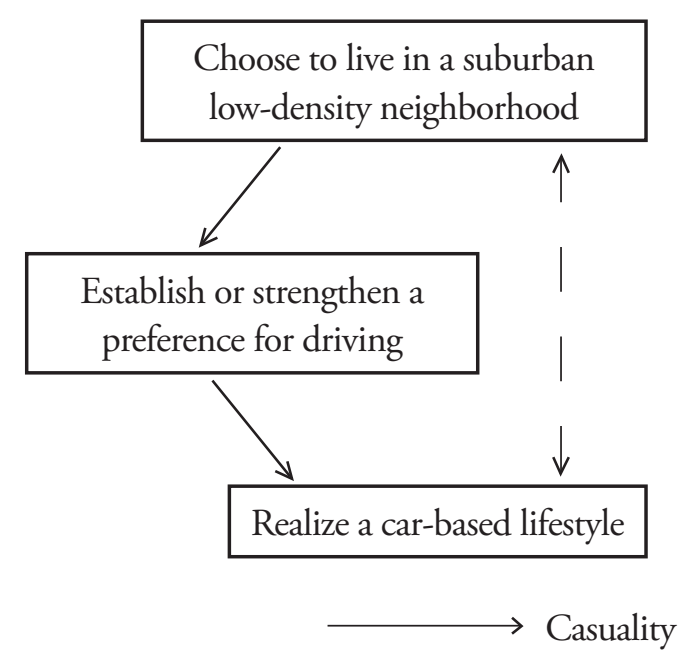

b. Attitudes Intervening

(in one direction)

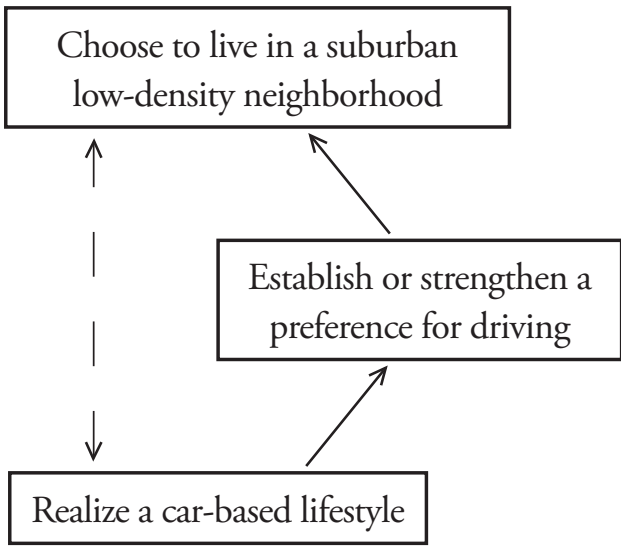

d. Attitudes Secondary and Bidirectionally Related

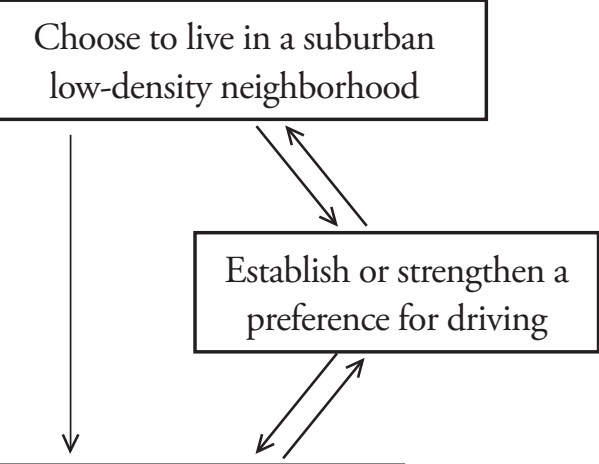

Realize a car-based lifestyle

Figure 2: Some potential relationships among travel attitudes, built environment, and travel behavior (adapted from Cao et al. 2009).

It appears plausible that those who live in an area where they feel strongly dependent on car travel in daily life will develop more positive attitudes towards the car. Conversely, inner-city residents who do not at all need to use the car in their daily life, but are exposed to traffic noise and emissions in their neighborhoods, might develop more negative attitudes to private motoring and a higher awareness about urban environmental problems.

A multivariate regression analysis among respondents of the above-mentioned Copenhagen Metropolitan Area study (Næss 2006a, b and 2009) shows that a relationship between residential location and transport attitudes still exists after controlling for car ownership and a number of demographic and socioeconomic variables. According to our material, the respondents' transport attitudes tend to become 
less car-oriented the higher is the local area density (Beta $=-0.115, \mathrm{p}=0.000)$. The effect of density probably partly reflects the lower car usage among residents of dense neighborhoods, as regular car travel (along with car ownership, which was also found to be influenced by residential location) must be assumed to exert a certain influence on transport attitudes. Moreover, the stronger exposure to congestion, noise and local air pollution experienced by residents of dense, inner-city environments may contribute to higher awareness about the negative environmental impacts of car traffic. Congestion on the local roads may also stimulate the use of other modes of travel than the car, and thus give experience which, in its turn, influences transport attitudes.

The introduction of more independent variables may provide more detailed information about factors influencing travel behavior. But if the purpose of the analysis is to identify and estimate the magnitude of the influence of residential location on travel, the inclusion of control variables that are related to residential location with two-way causality leads to an underestimation of the effect of urban structure. According to standard textbooks on multivariate analyses, the inclusion of an irrelevant control variable is a model misspecification equally serious as the omission of a relevant control variable (Lewis-Beck 1980; Hellevik 1988). If attitudinal variables are to be included in the analysis of relationships between built environment characteristics and travel behavior to control for the possible bias of residential selfselection, it is therefore crucial that the statistical method applied is able to deal with bidirectional relationships. Otherwise there is a risk that the self-selection control variables introduced to counteract bias will themselves create even more bias.

\section{e) People may have preferences for particular modes, but does anyone prefer to drive long distances rather than short?}

Much of the discussion on the role of transport-attitude-based residential self-selection as a potential source of error in studies of effects of built environment characteristics on travel behavior seems to be centered on choices of travel mode, especially for non-work trips. To the extent that the role of transportattitude-based residential self-selection in influencing traveling distances has been discussed, this has been seen as an indirect effect resulting from the replacement of long car trips with walking or biking trips to closer destinations when living in a neighborhood enabling residents to realize a preferred transport lifestyle based on increased use of physically active travel modes. However, much of the difference between people living at the urban fringe and their counterparts living in the inner suburbs in vehicle kilometers traveled can be attributed to shorter average trip distances rather than to differences in travel modes. For journeys to work, where the vast majority of employees have to travel beyond the confines of their ("walkable" or not) local neighborhood, it is also difficult to see how transport-attitude-based residential preferences could bias the relationships between residential location and traveling distances otherwise found. People certainly may have pre-existing preferences for certain travel modes inducing them to choose, for example, a suburban neighborhood if they like to travel by car, but does anybody really prefer long commuting distances and long trips to reach other daily activities?

\section{f) Activity preferences may be just as important as travel preferences in attitude-based residential self-selection}

There are some indications in the interview material from Copenhagen, Hangzhou and Oporto that attitude-based residential self-selection may be based just as much on activity preferences as on a wish to pursue a certain travel behavior lifestyle. In particular in the Oporto case, interviewees frequently consider that their activity pattern would change considerably if they lived in a different (more central 
or more peripheral than their existing residence) part of the metropolitan area. Also in the Copenhagen and Hangzhou cases several similar examples were found.

If the interviewee says he/she would have carried out an activity less if living at another location, this indicates that the present location is well-suited for carrying out that activity. This could be interpreted as an indication of activity-based residential self-selection. If, on the other hand, the interviewee says he/she would have carried out an activity more if living at another location, this would mean that the present dwelling is not optimal for the pursuit of that activity. This would indicate an example of distance decay, in contrast to activity-based residential self-selection. If the interviewee says that the activity would be carried out to the same extent, the conditions for pursuing the activity could either be spatially evenly distributed, or the interviewee would adjust for any differences in the local availability of activity opportunities by increasing (or decreasing) the distance traveled to reach the relevant facility. (Or, possibly, the interviewee is uninterested in the activity in question and will not engage in it regardless of how far or close the relevant facility is located.)

Based on the above lines of reasoning, activity-based residential self-selection seems to be present in all three urban regions. Several inner-city interviewees state that they think they would have carried out their current leisure activities less frequently if they lived in a more peripheral part of the urban area, since they would then not have so many offers of spaces and activity opportunities within accessible distance. Activities which would be conducted more rarely if living in a more peripheral area include evening classes, gym team exercise, badminton, socializing with neighbors, visits to restaurants, and going to the cinema. On the other hand, some suburban interviewees, especially in Copenhagen Metropolitan Area, consider that they would visit forests and other green areas less frequently, make fewer jogging trips, invite friends home more rarely and — perhaps needless to say—spend less time on gardening if they were to live in an inner-city neighborhood.

There are, however, also several interviewees in each city who do not think their activity pattern would change much if living in a different urban context. Moreover, some interviewees also say they would have engaged more in various leisure activities if they lived closer to relevant facilities, thus illustrating that distance from relevant facilities is sometimes a real obstacle to activity participation, also within an intra-urban context. For example, a non-car-owning female interviewee who had some years ago moved from the downtown area of Oporto to a suburb lamented the poorer activity opportunities in her new neighborhood. She considered that if she could return to living in the center of the metropolitan area, she could recover many habits that she once had. Another Oporto interviewee, a male car-owner, who had also moved from the inner city to a suburb, considered that his quality of life would be improved if he moved back to a more central neighborhood.

Residential location based on activity preferences may account for some of the observed "distance decay", i.e., differences in activity patterns often found between residents living at different distances from facilities (see, e.g., Næss 2006b). Activity-based residential self-selection could counteract some of the effects of residential self-selection based on transport attitudes, for example if a person who is strongly in favor of non-motorized and public transport is at the same time an outdoor recreation enthusiast. This person may end up choosing to live at the urban fringe close to a large natural area even if this neighborhood is poorly served by public transport and is located too far away from jobs and other facilities to make walking or biking viable options for daily-life travel.

The causal influence between activity preferences and residential location might, however, be the other way round: that growing up and living in an area with good outdoor recreation opportunities fosters an interest for such activities, whereas the opposite is the case for people living in a neighborhood without such opportunities. Given the long time that most of the interviewees had lived in their present neighborhoods — some of them all their life — the latter direction of causal influence may be as plausible 
as the former, at least among those with the longest time of residence in their present local area.

g) Travel attitudes are not the most important criteria of residential preferences, and several constraints can prevent people from realizing what they would otherwise prefer

The claim that self-selection represents a problem raising serious doubt about the influence of urban structure on travel rests with the assumption that many people actually choose their place of residence based on the opportunities and needs for travel by different modes provided in the chosen location. The extent to which people base their choices of place of residence on transport considerations may, however, be limited.

While preferences for a particular travel behavior lifestyle clearly can influence the kind of neighborhood in which a household would like to live, the possibility of pursuing a certain transport lifestyle is usually not the only concern reflected in a person's residential preferences. In practice, several, and maybe conflicting, residential preference criteria often have to be traded off against each other when deciding where to live (Næss 2009; Chatman 2009). As mentioned earlier, respondents of the studies in Copenhagen Metropolitan Area and Hangzhou Metropolitan Area were asked to select 3 out of a number of characteristics (17 in the Copenhagen study and 20 in the Hangzhou study) as the most important ones if they were to move from their present residence to a new dwelling. Looking at each metropolitan area as a whole, we find little evidence of transport-related self-selection on the respondents' actual residential locations. We have therefore limited the geographical scope of the following analyses to the respondents living within the more or less continuous urban area of Greater Copenhagen and the Hangzhou respondents living less than $10 \mathrm{~km}$ away from the main city center. With these city case demarcations, Table 1 shows the proportions of the respondents in each city case mentioning each of the listed preference criteria among the three most important. In the Greater Copenhagen study, the four main transport-related criteria (proximity to workplace, shopping opportunities, train station and bus stop) received $23 \%$ of the priorities, with a slightly lower priority level per criterion than the average for the remaining 13 preference criteria (Næss 2009) In the Hangzhou study the four main transportrelated criteria received $22 \%$ of the priorities, with a slightly higher priority level than the average for the remaining 16 preference criteria.

\begin{tabular}{|l|c|c|}
\hline Features of the dwelling & \multicolumn{2}{|c|}{$\begin{array}{c}\text { Proportion mentioning the } \\
\text { feature among the three } \\
\text { most important }(\%)\end{array}$} \\
\cline { 2 - 3 } & Copenhagen & Hangzhou \\
\hline No social problems in the neighborhood/area & 24.8 & 40.0 \\
\hline Low housing costs (i.e., a low rent, low mortgages etc.) & 27.7 & 35.9 \\
\hline Proximity to shopping opportunities & 25.0 & 32.1 \\
\hline Nice view from the dwelling & 18.1 & 32.0 \\
\hline Proximity to the residences of relatives and friends & 27.7 & 17.8 \\
\hline Private garden & 39.5 & 4.0 \\
\hline
\end{tabular}


Table 1: The importance attached by the respondents to selected characteristics of a possible new dwelling. Percentages of respondents who have mentioned various characteristics as one of the three most important.

\begin{tabular}{|l|c|c|}
\hline Proximity to the workplace & 21.6 & 21.5 \\
\hline High architectural and esthetic quality & 9.4 & 25.3 \\
\hline Proximity to recreational areas in forests, at shores or "in the countryside" & 27.9 & 4.7 \\
\hline Short distance for children to school/kindergarten & 15.1 & 14.5 \\
\hline Location at a sufficient distance from large traffic arteries (roads, railways) & 26.0 & 3.0 \\
\hline Proximity to a bus stop & 8.6 & 11.6 \\
\hline Proximity to a train station & 18.6 & 0.7 \\
\hline Good public facilities (Hangzhou study only) & ---- & 17.1 \\
\hline Good property management (Hangzhou study only) & ---- & 15.4 \\
\hline Location within a district/neighborhood that you know well & 9.0 & 6.0 \\
\hline Good opportunities for “do it yourself” activities-remodeling, keeping a garden etc. & 7.9 & 6.2 \\
\hline Undisturbed location, with ample distance to any neighbors & 7.4 & 4.3 \\
\hline Location away from apartment buildings and social housing & 4.4 & 1.4 \\
\hline Real estate company of good reputation (Hangzhou study only) & --- & 1.9 \\
\hline
\end{tabular}

Moreover, people are not always able to move to the desired type of neighborhood. Economic constraints are an obvious obstacle. Among the Greater Copenhagen respondents, 28\% mentioned "low hosing costs" as one of the three most important criteria, and among the Hangzhou respondents this proportion was as high as 36\%. In Hangzhou, there has been a steep increase in housing prices during the latest decades (Xue 2012, p. 124), which obviously can confine the opportunities of households for choosing residential addresses freely. Furthermore, nearly $40 \%$ of the Greater Copenhagen respondents mention a private garden among the three most important criteria and in Hangzhou nice view from the dwelling is mentioned by $32 \%$. Different needs and wishes among different household members can also prevent an individual from realizing his/her residential preferences. Maybe you want to live within biking distance from your workplace, but if your spouse works at the opposite side of the city of where your job is located, the chosen residential location may be a compromise where the wishes of each partner for short commuting distances are only partially fulfilled. As an illustration of this, "dissonant" respondents (i.e., residents living at locations poorly matching their transport-related preferences, cf. Figure 1) make up more than half of the Copenhagen Metropolitan Area respondents and more than $45 \%$ of the respondents of Hangzhou metropolitan area. Furthermore, it is a fallacy to assume that a resident living in a neighborhood conforming to his/her transport-related residential preferences has necessarily chosen this neighborhood in order to realize a preferred travel behavior lifestyle. The neighborhood can be chosen primarily for other reasons, for example because it is affordable or because it offers possibilities for gardening, while at the same time, as a secondary benefit, accommodating the travel behavior preferences of the resident.

In order to compare the influences of transport-related and other residential preferences on the respondents' actual residential locations with those of a number of demographic and socioeconomic variables, we have carried out multivariate regression analyses of the Greater Copenhagen data and data for Hangzhou respondents living less than $10 \mathrm{~km}$ from the city center. Table 2 shows the effects of the investigated variables on the distance from the dwelling to the city centers of Copenhagen and Hangzhou, respectively.

In Greater Copenhagen, two of the transport-related residential preference variables show significant effects on the distance between the dwelling and the city center: Preference for proximity to the workplace $($ Beta $=-0.126, \mathrm{p}=0.000)$ and preference for proximity to a train station (Beta $=0.140, \mathrm{p}$ 
$=0.000)$. Preference for proximity to the workplace appears to induce respondents to move closer to the city center, while preference for proximity to a train station appears to make them move to more peripheral locations. The latter effect may seem paradoxical, but what we see here is arguably an example of the reversed causality mentioned earlier under point $\mathrm{d}$ ): suburbanites may experience a greater need for easy access to urban rail transport than inner-city dwellers who can reach a broad range of jobs and other facilities within biking or walking distance.

In Hangzhou, none of the four residential preference variables assumed to be most clearly related to

Table 2: Results of a multivariate linear regression analysis of factors potentially influencing the distance (in $\mathrm{km}$ ) from the dwelling to the main city centers of Copenhagen and Hangzhou, respectively.

\begin{tabular}{|c|c|c|c|c|c|c|}
\hline & \multicolumn{2}{|c|}{$\begin{array}{l}\text { Unstandardized } \\
\text { coefficients }\end{array}$} & \multicolumn{2}{|c|}{$\begin{array}{l}\text { Standardized } \\
\text { coefficients }\end{array}$} & \multicolumn{2}{|c|}{$\begin{array}{l}\text { Level of significance } \\
\quad \text { ( } p \text { values) }\end{array}$} \\
\hline & $\begin{array}{l}\text { Copen- } \\
\text { hagen }\end{array}$ & $\begin{array}{l}\text { Hang- } \\
\text { zhou }\end{array}$ & $\begin{array}{l}\text { Copen- } \\
\text { hagen }\end{array}$ & $\begin{array}{l}\text { Hang- } \\
\text { zhou }\end{array}$ & $\begin{array}{l}\text { Copen- } \\
\text { hagen }\end{array}$ & $\begin{array}{l}\text { Hang- } \\
\text { zhou }\end{array}$ \\
\hline $\begin{array}{l}\text { Education level (measured in classes; above median = } 1 \text {, at or below } \\
\text { median = 0) }\end{array}$ & -3.442 & 0.505 & -0.261 & 0.109 & 0.000 & 0.000 \\
\hline Age & 0.088 & -0.013 & 0.196 & -0.068 & 0.000 & 0.022 \\
\hline Number of household members above 18 years of age & 1.619 & 0.157 & 0.149 & 0.057 & 0.000 & 0.018 \\
\hline $\begin{array}{l}\text { Personal annual income (in Copenhagen: measured in } 1000 \text { DKK, in } \\
\text { Hangzhou: measured in } 1000 \text { Yuan) }\end{array}$ & 0.0045 & & 0.175 & & 0.000 & $\begin{array}{c}\text { N.S. } \\
(\mathrm{p}=0.243)\end{array}$ \\
\hline Residential preference: Proximity to a train station & 2.431 & & 0.140 & & 0.000 & $\begin{array}{c}\text { N.S. } \\
(p=0.259)\end{array}$ \\
\hline Residential preference: Proximity to the workplace & -1.954 & & -0.126 & & 0.000 & $\begin{array}{c}\text { N.S. } \\
(p=0.241)\end{array}$ \\
\hline Residential preference: Private garden & 1.441 & & 0.106 & & 0.000 & $\begin{array}{c}\text { N.S. } \\
(\mathrm{p}=0.244)\end{array}$ \\
\hline $\begin{array}{l}\text { Whether the respondent holds a driver's license for car (yes }=1 \text {, no }= \\
0 \text { ) }\end{array}$ & & 0.547 & & 0.092 & $\begin{array}{c}\text { N.S. } \\
(p=0.579)\end{array}$ & 0.000 \\
\hline $\begin{array}{l}\text { Residential preference: Location away from apartment buildings and } \\
\text { social housing }\end{array}$ & 2.868 & & 0.085 & & 0.004 & $\begin{array}{c}\text { N.S. } \\
(p=0.686)\end{array}$ \\
\hline Workforce participation $($ yes $=1$, no $=0$ ) & & 0.445 & & 0.084 & $\begin{array}{c}\text { N.S. } \\
(p=0.521)\end{array}$ & 0.003 \\
\hline $\begin{array}{l}\text { Regular transport of children to school or kindergarten (yes }=1 \text {, no }= \\
\text { 0) }\end{array}$ & & 0.466 & & 0.081 & $\begin{array}{c}\text { N.S. } \\
(p=0.227)\end{array}$ & 0.001 \\
\hline $\begin{array}{l}\text { Residential preference: Proximity to the residences of relatives and } \\
\text { friends }\end{array}$ & & -0.486 & & -0.081 & $\begin{array}{c}\text { N.S. } \\
(p=0.482)\end{array}$ & 0.001 \\
\hline $\begin{array}{l}\text { Residential preference: Proximity to recreational areas in forests, at } \\
\text { shores or "in the countryside" }\end{array}$ & 1.214 & & 0.080 & & 0.006 & $\begin{array}{c}\text { N.S. } \\
(p=0.929)\end{array}$ \\
\hline Residential preference: No social problems in the neighborhood/area & & -0.365 & & -0.077 & $\begin{array}{c}\text { N.S. } \\
(\mathrm{p}=0.327)\end{array}$ & 0.001 \\
\hline Number of household members aged 7-18 & 0.592 & & 0.063 & & 0.040 & $\begin{array}{c}\text { N.S. } \\
(p=0.381)\end{array}$ \\
\hline $\begin{array}{l}\text { Residential preference: Location within a district/neighborhood that } \\
\text { you know well }\end{array}$ & & -0.582 & & $-0-059$ & $\begin{array}{c}\text { N.S. } \\
(p=0.718)\end{array}$ & 0.013 \\
\hline $\begin{array}{l}\text { Residential preference: Low housing costs (i.e., a low rent, low } \\
\text { mortgages etc.) }\end{array}$ & & -0.501 & & $-0-103$ & $\begin{array}{c}\text { N.S. } \\
(p=0.806)\end{array}$ & 0.000 \\
\hline
\end{tabular}




\begin{tabular}{|c|c|c|c|c|c|c|}
\hline & \multicolumn{2}{|c|}{$\begin{array}{l}\text { Unstandardized } \\
\text { coefficients }\end{array}$} & \multicolumn{2}{|c|}{$\begin{array}{l}\text { Standardized } \\
\text { coefficients }\end{array}$} & \multicolumn{2}{|c|}{$\begin{array}{l}\text { Level of significance } \\
\quad \text { ( } p \text { values) }\end{array}$} \\
\hline & $\begin{array}{l}\text { Copen- } \\
\text { hagen }\end{array}$ & $\begin{array}{l}\text { Hang- } \\
\text { zhou }\end{array}$ & $\begin{array}{l}\text { Copen- } \\
\text { hagen }\end{array}$ & $\begin{array}{l}\text { Hang- } \\
\text { zhou }\end{array}$ & $\begin{array}{l}\text { Copen- } \\
\text { hagen }\end{array}$ & $\begin{array}{l}\text { Hang- } \\
\text { zhou }\end{array}$ \\
\hline Residential preference: Proximity to a bus stop & & & & & $\begin{array}{c}\text { N.S. } \\
(p=0.110)\end{array}$ & $\begin{array}{c}\text { N.S. } \\
(p=0.280)\end{array}$ \\
\hline Residential preference: High architectural and esthetic quality & & & & & $\begin{array}{c}\text { N.S. } \\
(p=0.513)\end{array}$ & $\begin{array}{c}\text { N.S. } \\
(p=0.116)\end{array}$ \\
\hline Whether the respondent is a student/pupil (yes $=1$, no $=0$ ) & & & & & $\begin{array}{c}\text { N.S. } \\
(p=0.116)\end{array}$ & $\begin{array}{c}\text { N.S. } \\
(p=0.914)\end{array}$ \\
\hline $\begin{array}{l}\text { Residential preference: Short distance for children to school/ } \\
\text { kindergarten }\end{array}$ & & & & & $\begin{array}{c}\text { N.S. } \\
(p=0.365)\end{array}$ & $\begin{array}{c}\text { N.S. } \\
(p=0.120)\end{array}$ \\
\hline Residential preference: Nice view from the dwelling & & & & & $\begin{array}{c}\text { N.S. } \\
(p=0.739)\end{array}$ & $\begin{array}{c}\text { N.S. } \\
(p=0.132)\end{array}$ \\
\hline Sex $($ female $=1$, male $=0)$ & & & & & $\begin{array}{c}\text { N.S. } \\
(p=0.752)\end{array}$ & $\begin{array}{c}\text { N.S. } \\
(p=0.133)\end{array}$ \\
\hline $\begin{array}{l}\text { Residential preference: Good opportunities for "do it yourself" } \\
\text { activities' - remodeling, keeping a garden etc. }\end{array}$ & & & & & $\begin{array}{c}\text { N.S. } \\
(p=0.160)\end{array}$ & $\begin{array}{c}\text { N.S. } \\
(p=0.245)\end{array}$ \\
\hline $\begin{array}{l}\text { Whether the respondent had moved to the present dwelling less than } \\
5 \text { years ago (yes }=1, \text { no }=0 \text { ) }\end{array}$ & & & & & $\begin{array}{c}\text { N.S. } \\
(p=0.298)\end{array}$ & $\begin{array}{c}\text { N.S. } \\
(p=0.206)\end{array}$ \\
\hline $\begin{array}{l}\text { Residential preference: Real estate company of good reputation } \\
\text { (Hangzhou study only) }\end{array}$ & & & & & $\cdots$ & $\begin{array}{c}\text { N.S. } \\
(p=0.372)\end{array}$ \\
\hline $\begin{array}{l}\text { Residential preference: Undisturbed location, with ample distance to } \\
\text { any neighbors }\end{array}$ & & & & & $\begin{array}{c}\text { N.S. } \\
(p=0.486)\end{array}$ & $\begin{array}{c}\text { N.S. } \\
(p=0.578)\end{array}$ \\
\hline Residential preference: Good public facilities (Hangzhou study only) & & & & & $\cdots$ & $\begin{array}{c}\text { N.S. } \\
(p=0.579)\end{array}$ \\
\hline $\begin{array}{l}\text { Residential preference: Good property management (Hangzhou study } \\
\text { only) }\end{array}$ & & & & & $-\cdots$ & $\begin{array}{c}\text { N.S. } \\
(p=0.744)\end{array}$ \\
\hline Number of household members below 7 years & & & & & $\begin{array}{c}\text { N.S. } \\
(p=0.975)\end{array}$ & $\begin{array}{c}\text { N.S. } \\
(p=0.750)\end{array}$ \\
\hline $\begin{array}{l}\text { Residential preference: Location at a sufficient distance from large } \\
\text { traffic arteries (roads, railways) }\end{array}$ & & & & & $\begin{array}{c}\text { N.S. } \\
(p=0.761)\end{array}$ & $\begin{array}{c}\text { N.S. } \\
(p=0.845)\end{array}$ \\
\hline Residential preference: Proximity to shopping opportunities & & & & & $\begin{array}{c}\text { N.S. } \\
(p=0.856)\end{array}$ & $\begin{array}{c}\text { N.S. } \\
(p=0.819)\end{array}$ \\
\hline Constant & 1.887 & 4.528 & & & 0.043 & 0.000 \\
\hline
\end{tabular}

Only variables meeting a required significance level of 0.10 were included in the final regression model. N. S. = not significant at the 0.10 level. $\mathrm{N}=907$ (Greater Copenhagen) and 1676 (Hangzhou). Adjusted R²: 0.233 (Copenhagen) and 0.095 (Hangzhou). In Copenhagen Metropolitan Area the analysis includes only respondents from within Greater Copenhagen and in Hangzhou Metropolitan Area only respondents living within $10 \mathrm{~km}$ from the main city center. 
travel behavior shows significant effects on the distance between the dwelling and the city center. There is a tendency among Hangzhou respondents mentioning proximity to the residences of relatives and friends as a prioritized characteristic of the dwelling to live on average somewhat closer to the city center than the remaining respondents (Beta $=-0.081, \mathrm{p}=0.001$ ), but the importance of this variable in terms of transport-related residential self-selection is probably not very high.

Among the demographic and socioeconomic variables, the opposite signs of education level and age in Copenhagen compared to Hangzhou should be noticed. In Greater Copenhagen, young and well-educated people tend to live closer to the city center, whereas these population groups in Hangzhou tend to live further away from the city center. These findings illustrate the effects of a process of re-urbanization and gentrification that has been going on in Copenhagen for some decades. In Greater Copenhagen there is, however, also a tendency (albeit not as strong as those of education level and age) of living further away from the city center the higher is the income, whereas no effect of income on residential location relative to the city center can be found in Hangzhou.

In Greater Copenhagen, we find, controlling for the location of the dwelling relative to the city center, effects of residential preference for proximity to a train station on the distances from the residence to the closest urban rail station (Beta $=-0.149, \mathrm{p}=0.000$ ) as well as to the closest second-order center $($ Beta $=-0.063, \mathrm{p}=0.021)$. Moreover, respondents expressing preference for residential location close to a bus stop tend to live in local neighborhoods with slightly lower densities than the remaining respondents (Beta $=-0.047, \mathrm{p}=0.036$ ).

The effects of several demographic and socioeconomic variables on each of the residential location variables are, however, considerably stronger than those of the residential preference variables. The distance from the dwelling to the city center of Copenhagen is, for example, influenced by six demographic and socioeconomic variables with Beta values ranging from 0.053 to -0.251 . Similarly, the distance from the residence to the closest second-order center is influenced by six demographic and socioeconomic variables with Beta values ranging from -0.064 to 0.250 , the distance to the closest urban rail station by four demographic and socioeconomic variables whose Beta values range from 0.062 to 0.193 , and the local neighborhood density by three demographic and socioeconomic variables whose Beta values range from 0.057 to 0.172 .

In Hangzhou Metropolitan Area, the second-order and third-order centers are all located at least $14 \mathrm{~km}$ away from the main city center. Among the sub-sample of respondents living closer to the main city center than $10 \mathrm{~km}$ it was therefore not considered relevant to investigate the influence of transportrelated residential preferences to the location of their dwelling relative to these lower-order centers.

Compared to a regression model including only demographic and socioeconomic variables and the residential preference variables not clearly related to travel behavior, addition of the four transportrelated residential preference variables to the independent variables causes only a relatively modest increase in $\mathrm{R}^{2}$ values among the Greater Copenhagen respondents (from 0.232 to 0.246 ). For comparison, the $\mathrm{R}^{2}$ value of a model including only the demographic and socioeconomic variables is 0.203 . In the Hangzhou case, the inclusion of the four transport-related residential preference variables to a model already including the other 16 residential preference variables and the demographic and socioeconomic variables only increases the $\mathrm{R}^{2}$ value from 0.109 to 0.111 . (For comparison, a model including only socioeconomic and demographic variables shows an $\mathrm{R}^{2}$ value of 0.084 ,) In Greater Copenhagen, the four transport-related residential preference variables thus account for $5.7 \%$ and in Hangzhou only $1.8 \%$ of the explained variation in how far from the city center the dwelling is located, whereas the socioeconomic and demographic variables account for $83 \%$ and $76 \%$, respectively. The lesson to be drawn from this is that as long as the regression model comprises a wide range of demographic and socioeconomic variables along with the urban structural variables whose influences on travel behavior we want to inves- 
tigate, the inclusion of transport-related residential preferences as an additional control variable is hardly necessary. The socioeconomic and demographic variables seem to cover those individual properties that may predispose people to choose their place of residence based on preferences for a particular transport lifestyle. In sum these socioeconomic and demographic variables apparently work-at least in our two city cases - as satisfactory proxies for those aspects of residential preferences that may lead to transportattitude-based residential self-selection.

\section{$5 \quad$ Concluding remarks}

In this paper I have argued that the existence of transport-attitude-based residential preferences hardly represents any threat to the validity of the basic knowledge on how residential location within urban contexts influences travel behavior. Moreover, residential self-selection based on attitudes to travel is unlikely to represent any great source of error for parameter estimates of the effects of residential location variables on travel behavior if "traditional" demographic and socioeconomic variables have already been accounted for.

It has been argued that land use policies channeling most residential development to such areas as have been found to encourage short traveling distances, walking, biking and public transit usage may prove to yield less positive (from a sustainable mobility perspective) results than expected, because such a policy may suppress market demand for suburban, car oriented neighborhoods and hence force people with more car-oriented travel preferences to move into centrally located densification areas. If "carloving" people move to inner-city areas because this is where new dwellings are built, the argument goes, they are likely to drive more than existing (self-selected) "bike-loving" or "transit-oriented" residents in these areas. However, this argument disregards the fact pointed to above that travel behavioral attitudes may themselves be influenced by the needs for mobility, travel opportunities and transport cultures characterizing the residential neighborhood. The spatial urban development, changes in transport attitudes and changes in actual travel behavior in Oslo Metropolitan Area may serve as an illustration.

Oslo has pursued a pronounced densification policy since the mid-1980s (Næss, Næss \& Strand 2011). As a result, the population density within the continuous urban area (Greater Oslo, comprising 925,000 inhabitants in 2012) increased by as much as $29 \%$ over the period 1985-2011. The population density increase has been especially high in the central parts of Oslo. Within the so-called Inner Zone, the number of inhabitants grew by from 132.700 in 1989 to 184.500 in 2010, with no increase in the urbanized land, representing a population density increase of $39 \%$.

One might perhaps think that this would cause widespread dissatisfaction among parts of the population with car-oriented transport attitudes. According to theories of transport-related self-selection, a considerable exodus of "car-loving" people to exurban areas with better provision for automobile travel might perhaps be expected. However, nothing of this has happened. The population of Greater Oslo has grown by 215,000 over the last two decades (three quarters of which in the core municipality) and is forecasted to increase by another 300,000 over the next 20 years (Statistics Norway 2013). Population densities have also increased in the settlements in the part of the metropolitan area outside Greater Oslo. Furthermore, instead of staying constant, transport attitudes among the inhabitants of Oslo Metropoli$\tan$ Area have become more positive to public transport and non-motorized modes and more restrictive to car driving. According to an official report published by the National Road Authority, $40 \%$ were satisfied with the public transport services in 1989, and only $30 \%$ were positive to the road toll cordon. In 2012, the proportions of satisfied/positive had increased to $64 \%$ and $49 \%$, respectively. Since 2007 , the proportion stating that improved infrastructure for biking will make them cycle more has increased from $37 \%$ to $48 \%$. In 2012 , $84 \%$ consider that higher priority should be given to public transport, compared to $77 \%$ for biking, 51\% for walking and only 34\% for car driving (Sletten \& Gulbrandsen 
2012).

Not only have espoused transport attitudes changed, but actual travel behavior has also been altered. Vehicle kilometers traveled per capita have decreased since 2002 (Statens Vegvesen Region øst 2010), and there has been a quite remarkable change in the modal split during recent years. In 2007, $59 \%$ of commuting trips were made by car, $29 \%$ by public transport and $11 \%$ by non-motorized modes. In 2012, the proportion of car commuters had decreased to $46 \%$, whereas the shares of public transport and non-motorized modes had increased to 36\% and 16\%, respectively (Sletten \& Gulbrandsen, ibid.). (The remaining few percent were conveyed in a truck or a van.)

The doubts raised by certain scholars about the implications of attitude-based residential self-selection for the validity of the knowledge base of land use and transportation policies thus appear to be not very well-founded. Theoretical considerations, empirical evidence as well as practical experience from cities that have tried to promote sustainable mobility through land use strategies based on this knowledge suggest that the worry of whether residential location really matters to travel behavior could aptly be characterized as a tempest in a teapot.

\section{References}

Bagley, M. N. \& Mokhtarian, P.L. (2002) The impact of residential neighbourhood type on travel behaviour: A structural equations modelling approach. The Annals of Regional Science, 36 (2), pp.279297. http://link.springer.de/link/service/journals/00168/papers/2036002/20360279.pdf.

Beckmann, J. (2001) Risky Mobility. The filtering of automobility's unintended consequences. PhD Thesis. Copenhagen: University of Copenhagen.

Berry, B. J. L. \& Garrison, W. L. (1958) Recent Developments of Central Place Theory. Papers and Proceedings of the Regional Science Association, 4 (1), pp.107-120. doi:10.1111/j.1435-5597.1958. tb01625.x

Bhaskar, R. (1998) The Possibility of Naturalism: A Philosophical Critique of the Contemporary Human Sciences. $3^{\text {rd }}$ Ed. London and New York: Routledge. (First published 1979.)

Bhat, C. R. \& Guo, J. (2007) A comprehensive analysis of built environment characteristics on household residential choice and auto ownership levels. Transportation Research B, 41 (5), pp. 506-526. http://dx.doi.org/10.1016/j.trb.2005.12.005.

Boarnet, M \& Crane, R. (2001) Travel by Design. The Influence of Urban Form on Travel. New York: Oxford University Press.

Bothe, W. (2010) Residential self-selection and travel. The relationship between travel-related attitudes, built environment characteristics and travel behaviour. Amsterdam: IOS Press.

Bohte, W., Maat, K. Van Wee, B. (2009) Measuring attitudes in research on residential self-selection and travel behaviour. A review of theories and empirical research. Transport Reviews 29(3), pp. 325-357. doi:10.1080/01441640902808441.

Bruegmann, R. (2005) Sprawl: A Compact History. Chicago: Chicago University Press.

Cao, X. (2010) Exploring causal effects of neighborhood type on walking behavior using stratification on the propensity score. Environment and Planning A, 42, pp. 487-504. doi:10.1068/a4269.

Cao, X.; Mokhtarian , P. L. \& Handy, S. (2009) Examining the Impacts of Residential Self-Selection on Travel Behaviour: A Focus on Empirical Findings. Transport Reviews, 29 (3), pp. 359-395. doi:10.1080/01441640802539195.

Cao, X.; Xu, F. \& Fan, Y. (2010) Exploring the connections among residential location, self-selection, and driving: Propensity score matching with multiple treatments. Transportation Research Part A, 44, pp. 797-805. http://dx.doi.org/10.1016/j.tra.2010.07.010.

Chatman, D. W. (2009) Residential choice, the built environment, and nonwork travel: evidence using 
new data and methods. Environment and Planning A, 41, pp. 1072-1089. doi:10.1068/a4114.

Christaller, W. (1966) Central Places in Southern Germany. Englewood Cliffs, NJ: Prentice-Hall. (First published in German in 1933.)

Fox, M. (1995) Transport planning and the human activity approach. Journal of Transport Geography, 3 (2), pp.105-116. http://dx.doi.org/10.1016/0966-6923(95)00003-L.

Hägerstrand, T. (1970) What about People in Regional Science? Papers of the Regional Science Association, 24 (1), pp.7-21. http://onlinelibrary.wiley.com/doi/10.1111/j.1435-5597.1970.tb01464.x/abstract.

Hammond, D. (2005) Residential Location and Commute Mode Choice. MSc thesis. Cardiff: University of Wales.

Handy, S. (1996) Methodologies for Exploring the Link between Urban Form and Travel Behavior. Transportation Research D, 1 (2), pp.151-165. http://dx.doi.org/10.1016/S1361-9209(96)00010-7.

Heckman, J. J. (1979) Sample Selection Bias as a Specification Error. Econometrica 47 (1), pp.153-161. http://www.jstor.org/stable/1912352.

Hellevik, O. (1988) Introduction to Causal Analysis: Exploring Survey Data by Crosstabulation. ${ }^{\text {nd }}$ Ed. Oslo: Scandinavian University Press.

Jacobs, J. (1961) The Death and Life of Great American Cities. London: Pimlico.

Jones, P. (1978) Destination choice and travel attributes. In: Hensher, D. \& Dalvi, Q. (eds): Determinants of travel choice. New York: Praeger, pp.266-311.

Kitamura, R.; Mokhtarian, P.L. \& Laidet, L. (1997) A micro-analysis of land use and travel in five neighborhoods in the San Francisco Bay area. Transportation 24 (2), pp.125-158. doi:10.1023/A:1017959825565.

Lewis-Beck, M. (1980) Applied Regression. An Introduction. Series: Quantitative Applications in the Social Sciences, No. 07-022. Newbury Park/London/New Delhi: Sage Publication.

Nielsen, T. S. (2002) Boliglokalisering og transport i Aalborg. (Residential location and transport in Aalborg.) Ph.D. thesis. Aalborg: Aalborg University.

Næss, P. (2004) Prediction, Regressions and Critical Realism. Journal of Critical Realism 3 (1), pp.133-164. doi:10.1163/1572513041172713.

Næss, P. (2005) Residential Location Affects Travel Behavior - But How and Why? The case of Copenhagen Metropolitan Area. Progress in Planning 63 (2), pp.167-257. doi: 10.1016/j. progress.2004.07.004.

Næss, P. (2006a) Urban Structure Matters: Residential location, car dependence and travel behaviour. London/New York: Routledge.

Næss, P. (2006b) Accessibility, activity participation and location of activities. Exploring the links between residential location and travel behavior. Urban Studies 43 (3), pp.627-652. doi: 10.1080/00420980500534677.

Næss, P. (2009) Residential Self-Selection and Appropriate Control Variables in Land Use-Travel Studies. Transport Reviews 29 (3), pp.293-324. doi: 10.1080/01441640802710812.

Næss, P. (2010) Residential location, travel and energy use: the case of Hangzhou Metropolitan Area. Journal of Transport and Land Use 3 (3), pp.27-59. doi: http://dx.doi.org/10.5198/jtlu. v3i3.98.

Næss, P. (2011) 'New urbanism' or metropolitan-level centralization? A comparison of the influences of metropolitan-level and neighborhood-level urban form characteristics on travel behavior. Journal of Transport and Land Use 4 (1), pp.25-44. doi: http://dx .doi.org/10.5198/jtlu.v4i1.170.

Næss, P. (2013) Residential location, transport rationales and daily-life travel behavior: The case of Hangzhou Metropolitan Area, China. Progress in Planning 79 (1), pp.1-50. http://dx.doi. org/10.1016/j.progress.2012.05.001. 
Næss, P. \& Jensen, O. B. (2000) Boliglokalisering og transport i Frederikshavn. (Residential location and transport in Frederikshavn.) ISP publications no. 256. Aalborg: Aalborg University.

Næss, P. \& Jensen, O. B. (2004) Urban Structure Matters, Even in a Small Town. Journal of Environmental Planning and Management, 47 (1), pp.35-56. doi:10.1080/0964056042000189790.

Næss, P. \& Jensen, O. B. (2005) Bilringene og cykelnavet: Boliglokalisering, bilafhaengighed og transportadfard $i$ Hovedstadsområdet. (The car tires and the bike hub: Residential location, car dependency and travel behavior in Copenhagen Metropolitan Area.) Aalborg: Aalborg University Press.

Næss, P.; Næss, T. \& Strand, A. (2011) Oslo's farewell to urban sprawl. European Planning Studies 19 (1), pp.113-139. doi:10.1080/09654313.2011.530395.

Næss, P., Silva, C. \& Pinho, P. (2011) Residential location and travel in a polycentric city. Paper presented at the World Symposium on Transport and Land Use Research, July 28, 2011 in Whistler, Canada.

Pinho, P. \& Silva, C. (eds.) (2015) Mobility patterns and urban structure. Farnham: Ashgate (forthcoming).

Røe, P. G. (2001) Storbymenneskets hverdagsreiser. Sammenhenger mellom bosted, livsstil og hverdagsreisepraksis i et senmoderne perspektiv. Dr. Polit. thesis. Trondheim: Norwegian University of Technology and Science.

Sayer, A. (1992) Method in Social Science. A Realist approach. $2^{\text {nd }}$ Ed. London: Routledge.

Schwanen, T. \& Mokhtarian, P. L. (2004): The extent and determinants of dissonance between actual and preferred residential neighbourhood type. Environment and Planning B, 31, pp. 759784. doi:10.1068/b3039.

Sletten, Ø. \& Gulbrandsen, J. (2012) Holdningsunders $\varnothing$ kelse om bomring, trafikk og kollektivtilbud i Oslo og Akershus 1989-2012. (Survey of attitudes regarding toll ring, traffic and public transport provision in Oslo and Akershus 1989-2013.) PROSAM report no. 199. Oslo: National Road Authority, Region East.

Statens Vegvesen Region øst: Trafikkregistreringer i Oslo og Akershus 2009. (Traffic registrations in Oslo and Akershus 2009.) PROSAM report no. 185. Oslo: National Road Authority, Region East.

Statistics Norway (2013) Framskrevet folkemengde, etter region, tid og statistikkvariabel. (Population forecast by region, time and statistical variable.) Oslo: Statistics Norway, accessed February 5, 2013 at https://www.ssb.no/statistikkbanken.

Tillberg, K. (2001) Barnfamiljers dagliga fritidsresor i bilsamhället - ett tidspussel med geografiska og könsmässiga variationer. Geografiska regionstudier nr. 43. Uppsala: Uppsala University.

Tobler, W. (1970) A computer movie simulating urban growth in the Detroit region. Economic Geography 46 (2), pp.234-240.

Van Acker, V. \& Witlox, F. (2010) Car ownership as a mediating variable in car travel behavior research using a structural equation modelling approach to identify its dual relationship. Journal of Transport Geography 18(1), pp. 65-74. http://dx.doi.org/10.1016/j.jtrangeo.2009.05.006

van Wee, B. (2009) Self-selection: A key to a better understanding of location choices, travel behaviour and transport externalities? Transport Reviews, 29 (3), pp.272-292. doi:10.1080/01441640902752961

Van Wee, B. (2013) Land use and transport. In: van Wee, B.; Annema, J. A. \& Banister, D. (eds.) The transport system and transport policy. An introduction. Cheltenham, UK and Northampton, USA: Edward Elgar Publishing, pp.78-100.

Weaver, W. (1948): Science and complexity. American Scientist 36, pp.536-544. 
Xue, J. (2012) Potentials for decoupling housing-related environmental impacts from economic growth. Ph.D. thesis. Aalborg: Aalborg University.

Zhou, B. \& Kockelman, K. (2008) Self-selection in home choice: Use of treatment effects in evaluating the relationship between the built environment and travel behavior. Transportation Research Record, 2077 (8), pp. 54-61. http://dx. 